\title{
NOROC, IDEAL ŞI PESIMISM ÎN VERSURILE LUI MIHAI EMINESCU
}

\author{
Dr. Nicholas Andronesco \\ University of Bridgeport, Connecticut, USA, \\ Math.physics2@gmail.com
}

\begin{abstract}
În versurile lui Eminescu, conceptele de noroc şi ideal pot fi întâlnite ca expresii de sine stătătoare ca şi în corelaţie cu structura imaginilor poetice. Ne referim la versurile lui Eminescu pentru că în selecţia citatelor am apelat nu numai la poezie dar şi la versuri din piesele lui de teatru, transpunerea în versuri ale unor basme ca şi traduceri din poeţi din altă cultură. Comunicarea conţine două liste cu versuri de Eminescu cu cele două concepte pe care le-am analizat, cu un aparat statistico-matematic, folosind frecvenţele apariţiei lor pe anii de creaţie. Conceptele noroc şi ideal formează o unitate cibernetică (UC). Ele se determină reciproc. Pesimismul lui Eminescu se datorează cunoştinţelor de fizică ce le-a studiat în Germania la cursul profesorului Hermann von Helmholtz de la Berlin în anul 1872. Concluziile lui Eminescu sunt:

1. Omul nu este capabil să scadă sau să adauge nici-un atom în lume.

2. Teoria conservării energiei arată că nimic nu poate fi schimbat. Suma de energie a Universului este constantă.Ce se ia dintr-un loc se adaugă într-altul. Nu există câştig şi nici folos.

Cele expuse dovedeşte pesimismul lui Eminescu pe care 1-a aplicat în opera sa.

În versurile sale, Eminescu îşi manifestă pesimismul prin lipsa de noroc sau nevoia de noroc pentru a ajunge la un ideal. Neatingând idealul, norocul devine ne-noroc. De remarcat faptul că pe lângă influenţele ce le-a primit de la filozofia germană şi filosofia şi religiile orientale, studiile de fizică îi aduc o poziţie originală în pesimismul exprimat. Această descoperire pune capăt confruntării între literaţi asupra pesimismului lui Eminescu.
\end{abstract}

PARTEA I NOROC Şi IDEAL În poezia eminesciană norocul şi idealul (o suveică a timpului) pot fi întâlnite ca expresii de sine stătătoare ca şi în corelaţie cu structura imaginilor poetice şi filosofice care pot fi deduse, presupuse prin stările sentimentale cărora le dau naştere contextele poetice, chiar metaforizarea întregii poezii. În versurile lui Eminescu descoperim patru moduri de a exprima conceptele la care ne referim:

1. Noroc

2. Ideal

3. Corelaţie (ne)noroc-ideal

4. Ideal reieşit din context Conceptul de ideal reieşit din substanţa poetică este întâlnit în aproape întreaga sa poezie chiar numai prin simpla intenţie de a crea catarsis, de a bucura pe cel ce se împărtăşeşte din izvoarele cunoaşterii şi trăirile înalte.

Concret, conceptul ideal este întâlnit de 16 ori şi conceptul noroc se întâlneşte de 70 de ori. Pesimismul se remarcă în multe din aceste contexte mai ales prin înţelesul de ne-noroc. 


\section{LISTA CU CONCEPTELE NOROC ŞI IDEAL INSERATE ÎN CONTEXTUL A DOUĂ VERSURI}

1. Lida (1866)

Și-n adâncu-i zugrăvește

Prin ruini un ideal.

2. Ondina (1866)

A idealului iese minune, Astfel prin notele lirei de-amor...

3. Din străinătate (1866)

Să pot a binezice cu mintea-nflăcărată Visările juniei, visări de-un ideal.

4. Întunericul şi poetul (1869)

Dar nu-s colori destule în lume să-nveșmânte A munților Carpatici sublime idealuri...

5. Romancero español (1870)

Şi de ce tu să te superi, Ideal al lui Moretto...

6. Epigonii(1870)

Voi, pierduți în gânduri sunte, convorbeaţi cu idealuri;

Noi cârpim cerul cu stele, noi mânjim marea cu valuri...

7. Venere şi Madonă (1870)

Ideal pierdut în noaptea unei lumi ce nu mai este,

Lume ce gândea în basme şi vorbea în poezii...

\section{Venere şi Madonă (1870)}

Ţi-am dat palidele raze ce-nconjoară cu magie

Fruntea îngerului-geniu, îngerului-ideal...

\section{Eco (I)(1872)}

Sau cum din zilele poetic june

A idealului iese minune.

10. În vremi demult trecute... III (1872)

Pot s-o topesc în forma de lut care s-o poarte Şi idealu-eteric în lut eu pot să-l prind, .. 11. Cugetările sărmanului Dionis(1872)
Filosof de-aş fi - simţirea-mi ar fi vecinic la aman!

În prelegeri populare idealele le apăr...

12. Povestea magului călător în stele VII(1872)

Pot s'o topesc în forma de lut care s'o poarte Şi idealu - eteric în lut eu pot să-l prind.

13. Iar faţa ta e străvezie(1876)

$\mathrm{Tu}$, chip chinuitor de dulce,

Tu, ideal în ochii mei...

14. De-atâtea ori... (1880)

Şi viaţa toată mi-am închis

Gonind la idealuri...

15. Dintre sute de catarge (1880)

De-i goni fie norocul,

Fie idealurile...

16. Luceafărul (1883)

Ei numai doar durează-n vânt

Deşerte idealuri...

\section{NOROC}

1. Resignaţiune (din Shiller) (1867)

Vei ține socoteală de cei nenorociți.

Aci espatriatul o patrie găsește...

2. Resignaţiune (din Shiller) (1867)

Tu ai sperat răsplata ți-a fost dar acordată $\neg$

Speranța-i bunul care norocu-ți destina.

3. Amorul unei marmure(1868)

Şi te iubesc, copilă, cum repedea junie Iubeşte-n ochi de flacări al zilelor noroc...

\section{Cine eşti(1868)}

$\mathrm{N}$-am izbutit de mine destul a-mi bate joc

De mai apari în visu-mi... o rază de noroc? 
5. Viaţa mea fu ziuă(1869)

Pe cerul vieței mele; iar geniul-noroc

Mă lasă-n lume singur, dispare în abis.

6. Viaţa mea fu ziuă(1869)

Norocul și-a stins steaua... De m-ai iubi

măcar $\neg$

O, înger de amar!

\section{Venere şi Madonă (1870)}

Şi-am făcut din tine-un înger, blând ca ziua de Căci te-am văzut cum nu te-a văzut nime. magie,

Când în viaţa pustiită râde-o rază de noroc.

8. Daţi-mi arpă de aramă(1870)

Dar cu inimă regală

Şi cu flamuri de noroc.

9. Romancero español (1870)

$\mathrm{Cu}$ Madona lui Moretto,

Atunci ești nenorocită.

10. Doi aştri(1872)

Înger cu lumine

De-un adânc noroc.

\section{1. Împărat şi proletar(1874)}

Chiar clopotul n-a plânge cu limba lui de spijă

Pentru acel de care norocul avu grijă...

12. În căutarea Sheherezadei I (1874)

$\mathrm{Nu}$ crede însă că în doruri vane

Caut norocul spre-a te-afla pe tine,

13. În căutarea Sheherezadei I (1874)

Noroc lumesc zâmbiri aeriane!

14. Rugăciunea unui dac(1875)

Astfel numai, Părinte, eu pot să-ţi mulţumesc

Că tu mi-ai dat în lume norocul să trăiesc.

\section{Călin Nebunul IV (1875)}

Dară pe cea mijlocie, mi-o căzut dragă de foc Şi nici ea nu zice baiu, bat-o hâtrul de noroc.

16. Fata-n grădina de aur I (1875)

Auzi feciorul de-mpărat Florin, Norocul lui cu-al ei îi pare geamăn...
17. Fata-n grădina de aur II(1875)

Îti dau o pasăre cu tine zboară

$\mathrm{Cu}$ calul tău, unde norocu-ți crește.

18. Fata-n grădina de aur IV (1875)

Din cărți o soaţă-a ei îi sta să-i spună

C-al ei noroc purtatu-i de un fante.

19. Fata-n grădina de aur IV (1875)

Ah, aș muri de-atât noroc și bine,

20. Icoană şi privaz(1876)

Dar unde este dânsul cu geniu-i de foc

Şi eu, fire hibridă copil făr- de noroc!

21. Icoană şi privaz(1876)

Făr- de noroc? De ce dar? Au nu sunt fericit

Că-n calea mea o umbră frumoasă s-au ivit?

22. Gândind la tine(1876)

Ce mi-a fost dat să-1 strâng o clipă-n brață?

$\mathrm{Tu}$, blond noroc al unui vis desert...

23. Gândind la tine(1876)

Tu, visul blond unui noroc ce nu e,

De-i mai veni, să știi că nu te iert.

24. Cu-amândouă mâinile (1876)

Un noroc asemenea

Blând şi dureros!

25. Cu-amândouă mâinile (1876)

Un noroc asemenea

Blând şi dureros!

26. Călin IV (1876)

$\mathrm{O}$, rămâi, rămâi la mine, tu, cu viers duios de foc,

Zburător cu plete negre, umbră fără de noroc.

\section{Călin VIII (1876)}

Îi foşnea uscat pe frunze poala lungă-a albei rochii,

Faţa-i roşie ca mărul, de noroc i-s umezi ochii;

28. O stradă prea îngustǎ (1876)

Şi ai venit chiar tu!

Am așteptat norocul. 
29. O stradă prea îngustă(1876)

Norocu-acesta nu.

Cum dete preste mine?

30. Cântec vechi (1876)

Suspinând şi ameţit

Mă simt mai nenorocit

31. Mureşanu I (1876)

$\mathrm{Nu}$-ntreb de ce în lume nu ni e dat de soarte

Noroc făr- de durere, viață făr- de moarte $\neg$

32. Mureşanu I (1876)

O, eu nu cer norocul, dar cer să mă înveți

Ca viața-mi preț să aibă și moartea-mi s-aibă preț.Cei plini de lacrimi şi noroc.

33. Mureşanu V (1876)

Din insulele sfinte străbat cântări ferice,

Noroc și desperare le văd unite-aice

34. Mureşanu V (1876)

Aicea nu ți-e locul, norocul eu nu-l caut, A lumii glasuri multe și glasul tău eu n-aud...

35. Să ţin încă o dată... (1876)

Ş-apoi să plec în lume,

Copil făr- de noroc.

36. Departe sunt de tine...(1878)

Departe sunt de tine şi singur lângă foc,

Petrec în minte viaţa-mi lipsită de noroc.

37. Departe sunt de tine...(1878)

O! glasul amintirii rămâie pururi mut,

Să uit pe veci norocul ce-o clipă l-am avut...

38. Povestea codrului(1878)

Şi să fim di n nou copii,

Ca norocul şi iubirea.

39. Foaia veştedă (1879)

Voi păstra întreg amarul

Şi norocul ăstor foi...

40. Minte şi inimă I(1879)

$\mathrm{Nu}$-i jignire în iubire,

Ci noroc și mângâiere

41. Minte şi inimă IV(1879)

Căci acestea nu-s nimică contra gingașei iubire.

Voi, în crudă tinereță, amândoi nenorociți...
42. Te duci... (1879)

S-a dus pe veci norocul meu -

Redă-mi comoara une i clipe.

43. Urât şi sărăcie (1879)

Când pentru o privire dai viaţă, dai noroc,

Când lumea ți-este neagră de nu ești la un loc.

44. Urât şi sărăcie (1879)

$\mathrm{Cu}$ ea... Unde-i norocul ce l-a promis ea ție?

Ce va rămâne vouă? Urât și sărăcie!

45. Atât de fragedă(1879)

S-atârnă sufletu-mi de ochii

46. O, stingă-se a vieţii... (1879)

Noroc fără durere, viață fără moarte.

Am pus demult deoparte acele roase cărți

47. O, stingă-se a vieţii... (1879)

O, eu nu cer norocul, dar cer să mă învăt

Ca viața-mi preț să aibă și moartea s-aibă preț.

48. Despărţire(1879)

La ce simţirea crudă a stinsului noroc

Să nu se sting-asemeni, ci-n veci să stea pe loc?

49. Despărţire(1879)

Când voi să-mi piară urma în mintea tuturor,

Când voi să uiţi norocul visat de amândoi.

50. Sarmis(1879)

Şi plini îți erau ochii de lacrimi și de foc,

Pe-al genei tale tremur purtând atât noroc...

51. Stelele-n cer(1879)

Orice noroc

Şi-ntinde-aripile...

52. Strigături (1879)

Oricât fii nenorocită

Tot cu dragostea te iei.

53. Ta twam asi(1879)

Oamenii salută-n cale pământeasca zeitate.

Tu te-nchini. Te simți născută spre norocul tuturora.

54. Dintre sute de catarge (1880)

De-i goni fie norocul,

Fie idealurile... 
55. Mănuşa (1881)

Ce-i promite că norocu-i e aproape. -

Dar mănuşa el în faţă i-o aruncă...

56. Scrisoarea I(1881)

De a vieţii lor enigmă îi vedem pe toţi munciţi,

Făr-a şti să spunem care ar fi mai nenorociţi.

\section{S crisoarea IV (1881)}

Pe când mâna ta cea albă părul galben îl netează.

Vino! Joacă-te cu mine... cu norocul meu... mi-aruncă

\section{Gemenii II-III (1881)}

Și cum pieriră toate pe rând precum venire

Şi cum cătând norocul mormântul și-l găsiră.

59. Gemenii II-III (1881)

În lumea de mizerii şi lacrimi nu e loc

Pentru atâta milă şi pentru-atât noroc...

60. Ce te legeni?... (1882)

Ducând gândurile mele

Şi norocul meu cu ele

61. Ochiul tău iubit(1882)

Şi te va găsi

$\mathrm{Cu}$ noroc.

62. Şi oare tot n-aţi înţeles... (1882)

Dorința să-l alunge

Dup-un noroc atât de sfânt.

\section{PARTEA II ANALIZǍ STATISTICǍ}

Apariţia conceptelor noroc şi ideal este dată cu anul când creaţia poetică a fost definitivată sau când a fost prima dată publicată. Următoarele tabele descriu frecvenţele celor două concept.

Tabel 1. Frecvenţa conceptelor NOROC şi IDEAL în versurile lui Eminescu

\begin{tabular}{|c|c|c|c|c|c|c|c|c|c|c|c|c|c|c|c|c|c|c|c|}
\hline Anii & $\begin{array}{l}18 \\
66 \\
\end{array}$ & 67 & 68 & 69 & 70 & 71 & 72 & 73 & 74 & 75 & 76 & 77 & 78 & 79 & 80 & 81 & 82 & 83 & Total \\
\hline Vârsta & 16 & 17 & 18 & 19 & 20 & 21 & 22 & 23 & 24 & 25 & 26 & 27 & 28 & 29 & 30 & 31 & 32 & 33 & \\
\hline Noroc & 0 & 2 & 2 & 2 & 3 & 0 & 1 & 0 & 3 & 6 & 16 & 0 & 3 & 15 & 1 & 5 & 3 & 8 & 70 \\
\hline Ideal & 3 & 0 & 0 & 1 & 4 & 0 & 4 & 0 & 0 & 0 & 1 & 0 & 0 & 0 & 2 & 0 & 0 & 1 & 16 \\
\hline
\end{tabular}

63. Iar când voi fi pământ (1883)

Mormânt făr' de noroc

Şi fără prieteni.

64. Luceafărul (1883)

Ei, Cătălin, acu-i acu

65. Luceafărul (1883)

Ei doar au stele cu noroc

Şi prigoniri de soarte...

66. Luceafărul (1883)

Pătrunde-n codru şi în gând,

Norocu-mi luminează!

67. Luceafărul (1883)

Trăind în cercul vostru strâmt

Norocul vă petrece...

68. S-a dus amorul...(1883)

Pentr-un atât de sfânt noroc

Străbătător durerii!

69. O stea în reci nămărginiri (1883)

O umbră-a stinsului noroc

Rămâne-n univers.

70. Ştefan cel Mare (schiţe de imn) (1883)

Și lumea privească un semn de noroc

Pe orișice culme înaltă. 
Tabel 2. Frecvențele cumulate pe două perioade a conceptelor NOROC și IDEAL în versurile lui Eminescu.

\begin{tabular}{|l|l|l|l|}
\hline Anii & $1866-1874$ Perioada 1 & $1875-1883$ Perioada 2 & Total \\
\hline Vârsta poetului & $16-24$ & $25-33$ & \\
\hline Noroc & 13 & 57 & 70 \\
\hline Ideal & 12 & 4 & 16 \\
\hline
\end{tabular}

Perioadele sunt determinate de la începutul creaţiei poetice până la terminarea studiilor universitare la Berlin şi după această perioadă când pesimismul lui devine nota fundamentală. Doar un singur an mai reuşeşte palid să încerce tăria idealului în 1880 când noroc apare o dată şi ideal de două ori. Anul 1870 este un an nodal. Cele două concepte apar de şapte ori: trei noroc şi patru ideal.

După anul 18883 apar creaţii până 1887 dar ele nu mai conţin nici noroc nici ideal. Era deja îmbolnăvit.

Conform cu anii ce însoţesc creaţiile în versuri, frecvenţele de apariţie a celor două concepte nu sunt egale. Este de înţeles că la unele poezii Eminescu a lucrat mai mulţi ani. Am ales anul în care poezia a fost terminată şi/sau prima data publicată. Ca resurse de identificarea operei poetice şi datarea ei am folosit Opere. Vol I Poezii ${ }^{3}$ de Eminescu, coordonatorul ediției acad. Mihai Cimpoi, EMINESCU, M. (1981). Fragmentarium. ${ }^{4}$ Ediție după manuscrise, cu variante, note, addenda şi indici de Magdalena D. Vatamaniuc ca şi website-uri https://poetiinostri.ro/mihai-eminescu-autor- $15 / 5$ şi http://www.poezie.ro/index.php/poetry/1736 12/O_stea_in_reci_nemarginiri

Din Tabelul 1 putem calcula un indice de semnificaţie ca raport între incidenţa conceptului noroc şi a conceptului ideal.

$R_{1}=N_{n} / N_{i}=70 / 16=4.38=438 \%$ Este evident că Eminescu a fost preocupat de noroc.

În Tabelul 2 am împărţit perioada de creaţie în două părţi egale cumulând frecvenţele celor două concepte.

$$
\begin{aligned}
& R_{2}=N_{n 1} / N_{i 1}=13 / 12=1.08 \\
& R_{3}=N_{n 2} / N_{i 2}=57 / 4=14.25
\end{aligned}
$$

Rezultă cu claritate că în prima jumătate de interval, 1866 - 1874, Eminescu a fost preocupat aproape în mod egal de cele două concepte. Pentru ideal sunt 12 apariţii şi pentru noroc 13 apariţii. Perioada a doua, 1875 - 1883, aparţine copleşitor norocului cu 57 de apariţii în timp ce idealul abia apare de 4 ori. Este evident că norocul devine obsesiv. Este în mod esenţial ceea ce i-a lipsit şi ceea ce l-a legat definitiv de pesimism. Remarcăm cu toată convingerea că a doua perioadă care începe cu anul 1875 urmează imediat după experienţele lui de fillosofie, de ştiinţe şi mai ales de fizică de la Universitatea Humboldt din Berlin.

Spre sfârşitul perioadei de creaţie poetul apropie norocul de ideal la nivel de finalitate a acţiunii. Amândouă sunt gonite, se duc sau pleacă. Eminescu ne transmite din nou melancolie şi pesimism.

\section{Dintre sute de catarge (1880)}

De-i goni fie norocul

Fie idealurile

Te urmează în tot locul

Vânturile, valurile.

(Fie) norocul şi (fie) idealurile se găsesc la egalitate a plecării, dispariţiei. Dacă aceste versuri scrise în 1880 definesc un pesimism al marii plecări din viaţă prevestind sfârşituri, versurile următoare scrise în 1882 declară aproprierea propriului lui sfârşit. Pesimism. Pesimism. Pesimism. 
Ce te legeni? (1882)

Ducînd gîndurile mele

Şi norocul meu cu ele.

Ducînd idealurile mele

Şi norocul meu cu ele.

Echivalând gîndurile cu idealurile, constatăm ducerea idealurilor şi a norocului.

De remarcat că în întreaga lui creaţie în versuri norocul este folosit la singular pe când ideal, idealuri le întâlnim la singular şi plural. Ca notă specială subliniez folosirea de către Eminescu a cuvintelor compuse ne-noroc-it, ne-noroc-ită şi ne-noroc-iţi pentru a sublinia lipsa de noroc a fiinţelor umane.

În creaţia eminesciană, conceptele NOROC ŞI IDEAL formează o unitate cibernetică $\mathbf{U C}^{6}$. Ele se determină reciproc.

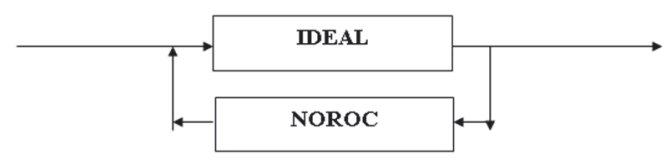

Tema tratată în acest studiu are multe valenţe de analizat. Trebuie să fie în atenţia cercetătorilor ştiinţifici să dezvolte noi studii şi aplicaţii.

\section{PARTEA FIZICǍ, POEZIE ŞI PESIMISM \\ CONSERVARE DE ENESRGIE = PESIMISM}

În creaţia sa literară şi ştiinţifică, Eminescu are o poziţie originală: pesimismul lui are strânsă legătură cu învăţăturilor din fizică ce le-a însuşit la Berlin în perioada cât a fost student în anii 1873-74 la Unversitatea Humboldt.

La Berlin 1-a avut ca profesor universitar pe Hermann von Helmholtz (1821 - 1894) care este numit la catedra de fizică a Universităţii Humboldt în anul 1871 la vârsta de 50 de ani. Fiind absolvent de faculate de medicină, înainte predase cursuri de anatomie, fiziologie şi psihologie la Academia de Arte Frumoase din Berlin şi la universităţile din Königsberg, Bonn şi Heidelberg. Disertatia lui de doctorat are titlul De fabrica systematis nervosi evertebratorum (1842). Iată cum îl caracterizează Enciclopedia Britanica:
Hermann von Helmholtz - German scientist and philosopher who made fundamental contributions to physiology, optics, electrodynamics, mathematics, and meteorology. $\mathrm{He}$ is best known for his statement of the law of the conservation of energy. He brought to his laboratory research the ability to analyze the philosophical assumptions on which much of 19th-century science was based, and he did so with clarity and precision [10].

Hermann von Helmholtz - Filosof şi om de ştiinţă german care a adus contribuţii fundamentale la fiziologie, optică, electrodinamică, matematică şi meteorology. El este cel mai cunoscut pentru definirea legii conservării energiei, El a adus în laboratorul său de cercetare capacitatea de a analiza ipotezele filosofice pe care ştiinţa secolului 19 este bazată şi a făcut-o cu claritate şî precizie.[10] [trad. Andronesco]

Traiectoria universitară şi de cercetări ştiinţifice a profesorului universitar Hermann von Helmholtz din Germania se aseamănă cu a lui Galileo Galilei (1564 - 1642) din Italia care a absolvit facultatea de medicină, dar a continuat cu predarea fizicii şi descoperirea de principii fundamentale în fizică. Eminescu scrie despre Galileo Galilei Si Isaac Newton în manuscrisele sale. De remarcat multitudinea subiectelor pe care le profesa Herr Helmholtz care devine pentru Eminescu un adevărat model după cum se poate constata mai ales din multele note şi comentarii ştiinţifice şi filosofice din Fragmentarium. Helmholtz publică cercetări ştiinţifice înspirate de medicină ca şi de fizică. Este cunoscut ca promotor al conservării energiei, electrodinamicii şi termodinamicii. Aceste domenii în fizică sunt cele ce-1 preocupă în mod deosebit şi pe Mihai Eminescu.

După ce 1-a avut student pe Eminescu, savantul Helmholtz a avut studenţi străluciţi nu numai la cursuri normale de fizică, ci şi la doctorate în fizică. Aceştia au adus contribuţii fundamentale la cunoaşterea şi dezvolarea fizicii. În 1877 Albert A. Michelson termină doctoratul îndrumat de Hermann von Helmholtz. Prin experimentele sale, el determină cu precizie viteza luminii în vid şi în aer. Prin celebrul experiment MichelsonMorley, Michelson demonstrează inexistenţa 
eterului luminous ceea ce duce la fundamentarea bazelor experimentale în teoria relativităţii. Un alt celebru student la doctorat în fizică ce 1-a avut pe von Helmholtz îndrumător este Heinrich Hertz descoperitorul undelor electromagnetice. Max Planck, autorul teoriei cuantice are acelaşi mentor la doctorat, pe Herr von Helmholtz. Elemente de cunaoaşterea fizicii ce urmau să ducă la marile descoperiri în fizică existau la savantul Hermann von Helmholtz încă de la începutul predării fizicii la universitate. Iată că Eminescu a avut ce învăța de la profesorul lui universitar de fizică.

În manuscrisul 2275 B Eminescu scrie: [33] Dar fiindcă nici o putere nu se risipeşte ci răsare sub altă formă - fiindcă cu cît apăsarea creşte, creşte mînia şi energia închisă a duşmanului nostru, cu cît victoria noastră a fost mai mare, cu atît numărul duşmanilor noştri au crescut, conform legii corelaţiunii creşterii, de aceea echilibrul se va restabili odinioară ${ }^{*}$ - victoria noastră $n u$ poate fi o victorie eternă — şi tot ce am aspirat în fundul sufletului nostru cu înălţime şi cu foc se reduce la zero dinamic - la o nouă stare de echilibru. De aci orice ştiinţă adevărată duce pe o parte la nepăsare, pe de alta la pesimism ${ }^{91}$. Toate sunt cum sunt noi $n^{92}$ le putem schimba. Precum nu putem scade sau adăuga in lume un atom, ci le $e^{93}$ putem numai aglomera în alt chip, precum nu putem scade sau adăuga din suma de energie a universului un milimetru măcar de ${ }^{94}$ mişcare, o secundă de repejune, astfel tot ce facem $^{95}$ e sau pentru a distruge un dezechilibru sau pentru a-1 crea. Ceea ce luăm dintr-o parte punem intr-alta - fără cîşstig, fără folos (p. 289) [4]

89, 90 Sublinierea cu două linii.

${ }^{91}$ pesimismul reprezintă, in accepţiunea de aici, expresia conştiinţei unor intelectuali, ca urmare a descoperirilor ştiinţifice din secolul trecut care arătau cît de puţine lucruri se ştiau despre fenomenele naturii şi ce limitate apăreau posibilităţile de cunoaştere ale omenirii în raport $\mathrm{cu}$ imensitatea tainelor Universului.

92 Scris deasupra.

${ }^{93}$ ci le, lecţiune aproximativă din cauza întinderii cernelii.
84 Urmează: mişcare (şters).

85 Urmează un cuvînt şters.

Nota 91 nu exprimă per se înţelesul dat de Eminescu pesimismului.

Subliniez în mod deosebit această notă a lui Eminescu: Victoria noastră nu poate fi o victorie eternă - şi tot ce am aspirat în fundul sufletului nostru cu înălţime şi cu foc se reduce la zero dinamic - la o nouă stare de echilibru. De aci orice ştiintă adevărată duce pe o parte la nepăsare, pe de alta la pesimism Aşadar:

1. Omul nu-i capabil a crea sau a distruge nici măcar un atom în univers

2. Teoria conservării materiei şi energiei îi dovedeşte lui Eminescu că nimic nu poate fi schimbat. Energia şi materia se conservă. Dacă o cantitate din energie se diminuează într-un sistem material, acea cantitate se regăseşte în alt sistem material cu care interacţionează.

Eminescu-i pesimist. La Eminescu lipsa de noroc defineşte pesimismul lui intrinsec ce-1 face şi mai nefericit. Covingerea lui ştiinţifică referitoare la "nu poţi crea sau distruge nici-un atom măcar în univers" aplicată la creaţia poetică este o teză originală şi universală a marelui Eminescu.

Atenţie! Norocul este întâmplarea în desfăşurare, procesul de a ajunge la ideal fără efort, ca o revelaţie. Norocul per se nu este un ideal. Aici putem lega acest proces de conceptul AHA din înţelesul ştiinţific al conexiunii la un moment dat al cunoştinţelor. Este vorba de momentul ACUM al conexiunii când piese separate de cunoaştere se leagă sinergic într-un înţeles ce te face să exprim Aha! Sau cum Arhimede ar fi exclamat la descoperirea principiului ce-i poarta numele Evrica. Cele expuse dovedesc foarte clar pesimismul ştiinţific şi poetic al lui Eminescu. Aceasta este o teorie originală, cu largi implicaţii în orice creaţie materială şî spirituală, ce îi aparţine în totalitate.

\section{Quot erat demonstrandum}

Pentru a întări şi mai mult poziţia de cunoaşterea profundă a fizicii de Mihai Eminescu adaug acestei comuniocări încă două citate din scrierile lui referitoare la conservarea momentului cinetic şi a energiei. Vorbesc şi de conservarea momentului cinetic 
cunoscut de Eminescu pentru a sublinia conceptul de conservare în fizică la o scară extinsă. Cantitatea de mişcare (momentul cinetic) se defineşte ca produsul dintre masa corpului şi viteza lui:

$$
\mathbf{p}=\mathbf{m v} \text { (Eminescu şi manual) [7] }
$$

Într-un sistem fizic izolat, momentul cinetic total se conservă ca vector. Această introducere se referă la textul următor, unde Eminescu foloseşte pentru viteză cuvântul repejune.

2267: La inceputul sutei ${ }^{778}$ trecute $s-a$ aprins asupra acestui punct o ceartă vie $e^{779}$ intre cele mai luminate spirite. Unii, cartesianii, în partea cărora s-a pus vestitul Voltaire $^{780}$ cu un anume tractat admiteau că: măsura mişcării este simplu productul de masă şi repejune. Contrarii, numiți leibniziani, pentru că părerea lor de Leibniz fusese mai întîi esprimată, admiteau că măsura mişcării este productul din masă şi din pătratul repejunii. După această din urmă părere e într-un corp o cantitate împătrită de mişcare dacă se mişcă c-o repejune îndoită. În partea acestei păreri găsim pe cei doi mari matematici Bernoulli ${ }^{781}$. Leibnizianii numeau acest product de masă multiplicat cu $^{782}$ pătratul repejunii putere vie. Vom întrebuința această espresie şi de aici inainte, dar vom zice cantitate de mişcare şi mărime a mişcării". [...] Adesea cearta dintre cartesieni şi leibniziani a fost declarată ceartă de cuvinte. Dar cu toată autoritatea lui D'Alembert ${ }^{784}$ nu este aşa. (p. 437)[4].

\footnotetext{
${ }^{778}$ Scris deasupra; iniţial: secolului (şters).

779 Scris deasupra; iniţial: vehementă (şters).

${ }^{780}$ Voltair (François-Marie Arouet) (1694

- 1778), scriitor şi gânditor francez. [...].

${ }^{781}$ Bernoulli, familie de matematicieni elveţieni. [...]

${ }_{782}$ multiplicat $\mathrm{cu}$, scris deasupra.

${ }^{783}$ Textul: "Vom intrebuinţa... mărimea mişcării", marcat pe margimne cu creion roşu.

784 Jean le Rond D'Alembert (1717 1783), filosof şi matematician francez. [...].

Eminescu ia o poziţie fermă referitoare la această dispută.[4] $\mathrm{Nu}$ este de accord cu d'Alambert şi are dreptate.

E greu de crezut că oameni ca Leibniz,
}

Voltaire, Benoulli să discute zeci de ani fără a băga de seamă, că nu e vorba decît de un malentendu. Dar nu este lesne de-a lămuri lucrul împrejurul căruia se-nvîrtea cearta. Mişcarea nu poate să dispară fără de urmă în lume, fără (p. 437) a lăsa un efect ${ }^{785}$. Dacă dar prin mijlocirea unei puteri oarecare mişcarea se transmite întreagă sau în parte de la o masă supra celeilalte fără ca să se intîmple altă schimbare sau alt efect, atunci pare apriori sigur că după transmisiune cantitatea de mişcare va fi intocmai atît de mare, precum fusese şi mai nainte. Conform acestora trebuie aleasă măsurătoarea mişcării şi conform acestui principiu credeau amândouă partidele, Cartesius şi Leibniz, că şi-au ales măsurătorile lor ale mişcării. Desigur că nu e o ceartă de cuvinte, cînd Cartesius zice că productul din masă şi repejune se conservă la transmiterea mişcăriii ${ }^{786}$ şi cînd Leibnitz zice că produsul din masă şi patratul repejunii se conservă la transmitere, dacă nu se exercită vreo altă influență, un adous ce nu trebuie a se uita ${ }^{787}$. E o ceartă obiectivă şi Leibnitz are cuvînt, adică măsurătorul mişcării sau a puterii vii este jumătate productul din masă multiplicat cu pătratul repejunii ${ }^{788}$. O piatră aşadar cînd zboară îndoit atît de repede, nu are o cantitate de mişcare îndoităa ci împătrită ${ }^{789}$. Această măsură a mişcării e însă totodată măsura cauzei prin care a fost produsă mişcarea ${ }^{790}$ (p. 438)[4].

${ }^{785}$ Sublinierea cu creion roşu.

${ }^{786}{ }_{789}$ Sublinierea cu creion roşu; la 790 cauzei subliniat mai accentuat.

Folosirea Leibnitz şi Leibniz aparţin textului original

Corectă este expresia din fizică a energiei cinetice ce o exprimă Eminescu:

$$
\mathbf{E}_{\mathbf{C}}=1 / 2 \mathbf{m v}^{2}
$$

Iată că marele poet naţional vorbeşte în formule concrete şi corecte de fizică. Chiar mai mult, ne dă explicaţii cum trebuie înţeleasă formula: adică măsurătorul mişcării sau a puterii vii este jumătate productul din masă multiplicat cu pătratul repejunii. O piatră aşadar cînd zboară îndoit atît de repede, nu are o cantitate de mişcare îndoită, ci împătrită. În versurile sale Eminescu îşi manifestă pesimismul prin lipsa de noroc şi 
nevoia de noroc pentru a ajunge la un ideal. Aceste studii îi aduc o poziţie originălă în pesimismul afirmat.

Conservarea energiei + Creaţie poetică $=$ Pesimism ştiinţific Eminescu

Această teorie originală a lui Eminescu explică pesimismul multor poeţi.

Aceastǎ legătură între conservarea energiei din fizică aplicată la creaţia poetică şi pesimismul lui ştiinţific o numesc:

\section{LEGEA UNIVERSALǍ EMINESCU}

\section{Concluzii şi recomandări}

De remarcat faptul că pe lângă influenţele ce le-a primit Mihai Eminescu de la filozofia germană şi filosofia şi religiile orientale, studiile de fizică îi aduc o poziţie originală asupra pesimismului. Această descoperire pune capăt confruntării între literaţi asupra pesimismului lui Eminescu.

Legea univerală Eminescu uneşte pentru prima oară în mod evident cele două metodologii ale cunoaşterii umane: cea de modelare specifică ştiinţ̧elor (Fizicii) şi cea metaforică specifică artelor (Poeziei). Ambele metodologii au la bază comparaţia care este metoda generală a cunoaşterii umane.

Pentru studiile viitoare recomand:

1. Un studiu atent asupra celor două vârfuri statistice ale frecvenţei pentru NOROC corespunzătoare anilor 1876 (16 apariţii) şi 1879 (15 apariţii). Încercaţi să le corelaţi cu evenimente din viaţa poetului.

2. Cum de apar de două ori ideal şi o dată noroc în anul 1880 ca şi de patru ori ideal şi trei ori noroc în anul 1870. Sunt singurele situaţii când frecvenţa corespunzătoare idealului depăşeşte pe cea a norocului.

3. Evident că această comunicare sugerează mult mai multe teme de studiat şi aprofundat. Succes!
NOTE ŞI REFERINŢE

Ideal - S. Adj. care atinge perfecţiunea; perfect; desăvârşit. 2. Adj. Care ţine de domeniul ideilor, privitor la gândire; care există numai în mintea şi închipuirea omului; spiritual; material. 3. S.n. Scopul suprem spre care se îndreaptă în mod conştient şi metodic omul; năzuinţele şi activitatea creatoare umană în toate domeniile ei, gândul cel mai înalt şi greu de ajuns al perfecţiunii într-o direcţie.

Noroc 1. S.n. soartă, reuşită, destin (favorabil) 2. Întâmplare neaşteptată sau concurs de împrejurări favorabile care asigură reuşita unei acţiuni; împlinirea unei dorinţe; baftă, etc. 3. Stare sufletească sau situaţie în care omul se simte fericit; fericire, bine. Numărul din dreapta şi deasupra textului cu litere roşii scris de Eminescu descrie numărul manuscrisului.

EMINESCU, M, (2001). Opere. Vol I Poezii. Coordonatorul ediției acad. Mihai Cimpoi, Editura Gunivas SRL, Chişinău, MD

EMINESCU, M. (1981). Fragmentarium. Ediție după manuscrise, cu variante, note, addenda şi indici de Magdalena D. Vatamaniuc. Editura Ştiinţifică şi Enciclopedică, București, România.

https:/poetii-nostri.ro/mihai-eminescu-autor-15/ ANDRONESCO, N. (2017). Discurs asupra metodei. Introducere în analiza ciberneticoliterară. Literatura şi Arta nr.18/2017, Chişinău, MD.

ANDRONESCO, N. (2018). FIZIOGRAFIA EMINESCU- GENESIS. Lumina Publishing House, Stamford, Connecticut, USA - In curs de aparitie.

http://www.poezie.ro/index.php/poetry/1736 12/O_stea_in_reci_nemarginiri

https://www.britannica.com/biography/Herm ann-von-Helmholtz

CONNECTICUT, USA

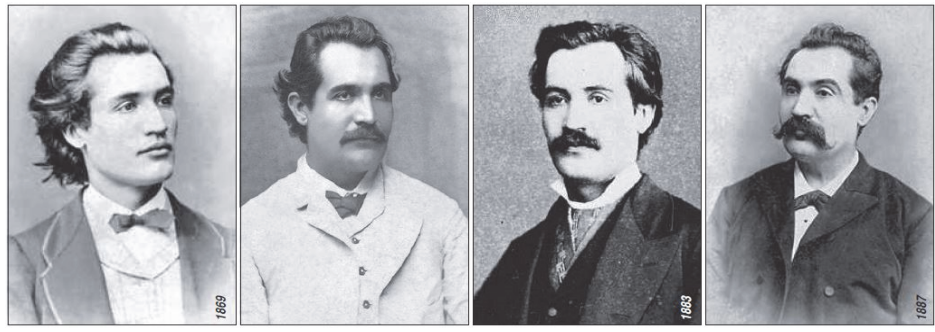

